\title{
CHARACTERIZATION OF CASE HARDENED AISI 4130 STEEL USING EDDY CURRENT TESTING
}

Casting is the manufacturing process of pouring the hot liquiduos state metal in to the mold cavity and then allowed it to solidify to obtain the final casting. There are many defects are found in the casting components during the inspection. Some defects are tolerated while others are required to repair. Otherwise the casting component is to be eliminated due to the poor quality level. The aim of the non-destructive inspection is to determine, the flaws, discontinuities on the material, and characteristics of the material. Based on the results by non-destructive evaluation the personnel take the decision on the material object is to be accepted or not as per the criteria. In this paper the hardness attribute of the case hardened AISI 4130 steel samples are studied using Vickers Hardness test. Then the hardness property is correlated with the Eddy Current Testing method. According to the acceptance criterion the suitability of the material is analyzed for the corresponding application or not. In this paper Eddy Current Testing response is analyzed for the AISI 4130 samples to determine the mechanical properties of the material. The main objective of the paper is to investigate the effect of the hardness property of the casting material during various case depth obtained via case hardening process. This technique is effective and best practice for the heat treatment shop floors. By this technique the results are investigated based on the cracks and microstructure of the casting material.

Keywords: AISI 4130, Casting Defects, Annealing, Hardness, Eddy Current Testing

\section{Introduction}

Non-destructive testing is one of the categories among the various testing methods to determine the characteristics of the material. The basic principle of this type of testing is to analyze the materials, components and assemblies without any physical impact in their structure for their future utilization. NDT study assists to know about the flaws in the structure of a product. NDT plays the main important role on the quality control of a product. The procedure is followed during the all stages of manufacturing. This kind of testing method plays as a main role to check the raw materials, fabricated products which are used to manufacture the end product before put into the service. Determination of martensite phase percentage is important to find the quality of the material before used in the application. There are two methods for measuring the percentage of martensite phase. The method named as metallographic inspection is performed by optical microscope. This destructive method is expensive and also time consumption is more. Another method of evaluation is eddy current testing (ECT). ECT is a non-destructive method based on the magnetic induction principle. ECT is one of the optimum methods among the various nondestructive testing methods to characterize the materials. It has been introduced as an industrial tool for micro structural inspections. ECT method is having the great potential, reliable, and cost effective among the traditional methods of quality control. Magnetic response of steel parts are sensitive based on their micro structure. By obtaining the ECT outputs, for the corresponding samples the characterizations are studied. ECT was used for checking the quality control of the heat treated parts. This technique assists to sorting the materials based on the mechanical properties of the corresponding samples. There are three types of probes used in eddy current testing. Internal probes are used for the testing of heat exchanger tubes during the service. Encircling probes are commonly used for testing the rods and tubes used for various purposes. The surface probes are used to locate the cracks on the material. Also this probes are used to sort of materials, measurement of wall and coating thickness, and case depth measurement. Konoplyuk [1] used this method for estimation of the pearlite percentage in ductile cast irons. This study reveals about the prediction of the matrix micro structure using the eddy current testing is possible for the various heat treatment process and chemical composition. Also, authors applied eddy current method for evaluation of ductile cast irons and showed that the ECT method can successfully predict the mechanical properties of cast irons [2]. Sadegh Ghanei [3] et al evaluate the dual phase steel by using ECT. This study correlates the eddy current testing outputs with the different percentages of martensite of the samples. By this analysis the martensite percentage of the unknown samples

\footnotetext{
* KONGU ENGINEERING COLLEGE, PERUNDURAI, TAMILNADU, INDIA

\# Corresponding author: gukendran.r@gmail.com
} 
are determined. Furthermore, this method is applied for the prediction of mechanical properties of the various ferrous metals. Rajkumar [4] et al studied the aging behavior of the M250 grade maraging steel by using ECT method. This study helps us to find the good assessment in the heat treatment shop floor. M. Zergoug [5] et al studied the relation between the mechanical micro hardness and impedance variations in the eddy current testing. This study analyzed about the mechanical and metallurgical characteristics of the various kind of heat treated material samples such as aluminium and steels. Mercier [6] et al analyzed the decarburizing depth of SAE 92V45 steel samples by eddy current testing technique. Initially the micro hardness is determined for the corresponding decarburized samples. Then the hardness is correlate with the eddy current response. T. Uchimoto [7] et al studied about the characterization of the various cast irons using eddy current testing method. This study investigates the characterization of various cast irons are predicted by means of correlation of the hardness results with the eddy current response of the corresponding samples. S.H. Khan [8] et al analyzed the pearlite determination of the various plain carbon steel samples. The effect of heat treatment on the samples causes to obtain the various percentage of pearlite content. In this heat treatment process the samples are cooled in furnace and half of the samples are cooled in the air. In this study the amount of the pearlite content is analyzed using the eddy current testing response. B.P.C. Rao [9] et al investigated the basics of Eddy Current Testing. Abbasian et al [10] studied the various precipitated hardened parts of Al-7075 are analyzed by coil probe at $6 \mathrm{KHz}$ of eddy current response. This technique was capable for the assessment of various precipitated hardened materials of Al-7075 parts this testing differs the various specimens based on the electrical conductivity.

In this study the microstructure of the various annealed temperature based AISI 4130 stainless steel casting specimens are found by optical microscope. Eddy current responses of these specimens are varied due to their different hardness value. This method helps us to investigate the mechanical characterization of the materials during the various annealing temperatures of the AISI 4130 material.

\section{Experimental procedure}

\subsection{Material composition}

Low alloy steels are possess the precise chemical compositions and provide better mechanical properties than many conventional mild or carbon steels. These alloy steels composition is comprised by 1 to 5 percent of various alloying elements. Those alloying elements are added based on their ability to provide a very specific attribute. In this experimental study AISI 4130 steel is taken to analyze the hardness using Eddy Current Testing method. The material composition of the AISI 4130 steel is given in Table 1.
TABLE 1

Material Composition

\begin{tabular}{|c|c|}
\hline Element & Percentage level (\%) \\
\hline Carbon & $0.28-0.33$ \\
\hline Manganese & $0.40-0.60$ \\
\hline Phosphorous & 0.035 \\
\hline Sulfur & 0.040 \\
\hline Silicon & $0.15-0.30$ \\
\hline Chromium & $0.80-1.10$ \\
\hline Molybdenum & $0.15-0.25$ \\
\hline
\end{tabular}

\subsection{Specimen preparation}

In this experimental study the AISI 4130 low alloy steel specimens are prepared at the diameter of $22 \mathrm{~mm}$ and at the length of $20 \mathrm{~mm}$. 5 specimens were prepared. Specimens are case hardened at various case depth of 0.2, 0.3, 0.4, 0.5, 0.6 (All dimensions are in $\mathrm{mm}$ ).By this surface hardening process the surface of the corresponding samples are gets hardened and the microstructure gets varied due to the impact of the case hardening process.

Initially the microstructures of the corresponding specimens are determined using the optical microscope by using Nital solution as an etchant. After finding the microstructure the hardness of the each specimens are determined using hardness testing machine. Hardness of the each specimen is plotted in a graph. It helps to identify the high hardness specimen. Then by using the eddy current testing the specimens are subjected to the test. This test was conducted by the assistance of eddy current hardness sorting tester. In this instrument coil probe is used to analyze the hardness of the various samples of the AISI 4130 steel. This test resulting the liftoff curve depends up on the micro hardness value of the material at various frequency ranges. These results are correlate with the hardness value of the each specimen. Coil probe is used to analyze the specimens and correlate the results with the hardness testing results. This study assists to determine the hardness characteristics of the AISI 4130 specimen at various annealing temperatures using ECT method. This method is most suitable for the sorting process of the various samples depend up on their hardness values, case depth, micro structure of the material and chemical composition. This method is used to analyze the properties of the samples with the mechanical tests.

\subsection{Microstructure of the AISI 4130 steel samples}

Figure 1 details about the micro structure of the Non Annealed AISI 4140 steel sample. Figures 2-5 details about the micro structure of the various heat treated AISI 4140 steel samples. The micro structures of the corresponding AISI 4140 Steel samples are determined using the optical microscope at $100 \times$ magnification ratio. From the figures the variation of the pearlite content is determined for the each samples. 


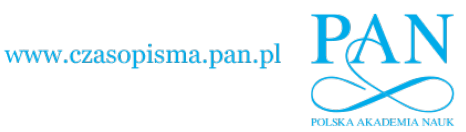

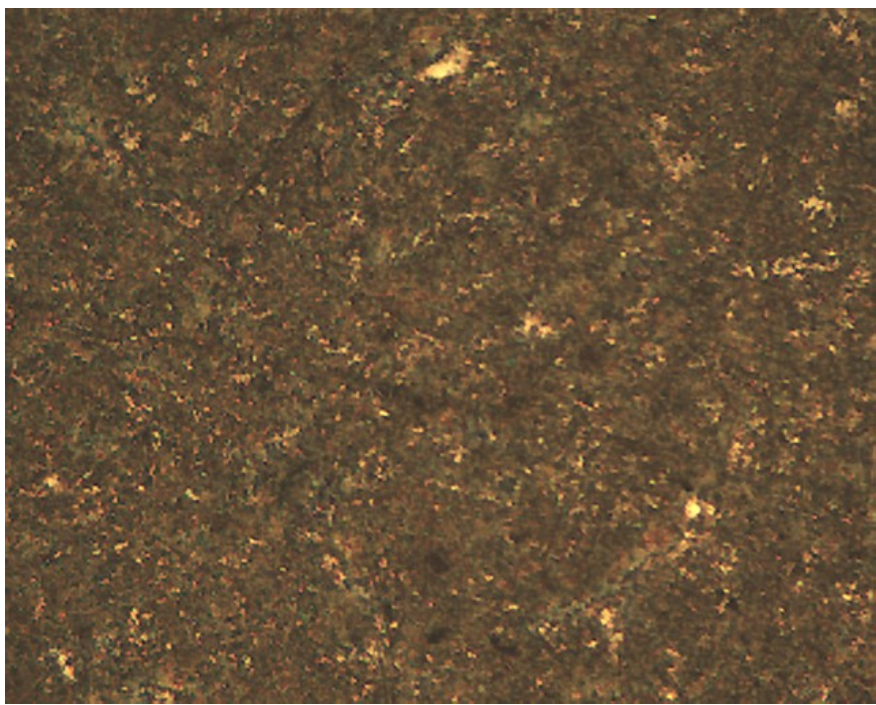

Fig. 1. Micro structure of Non-Annealed Sample

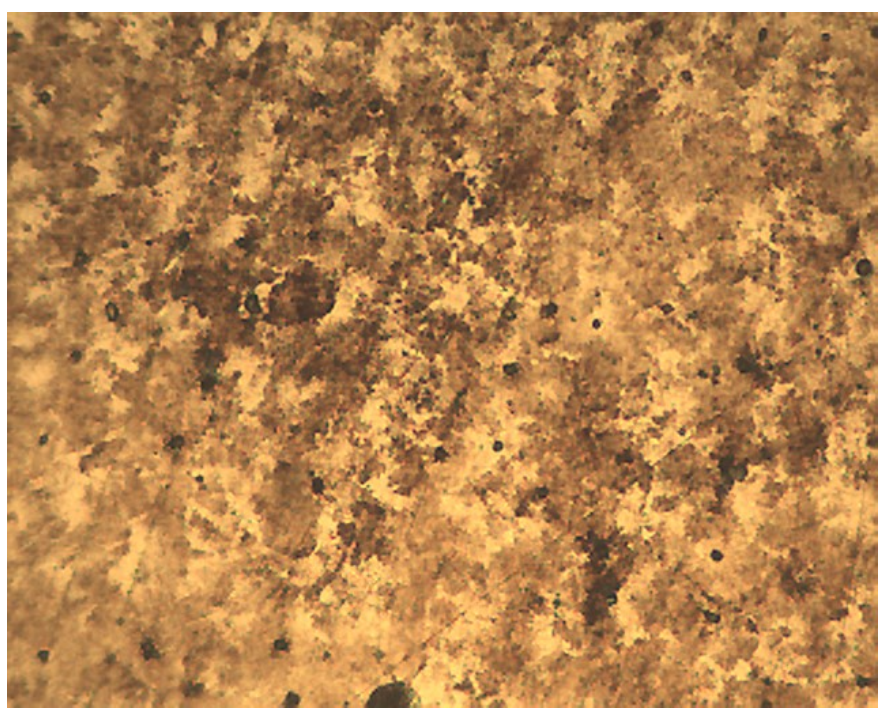

Fig. 2. Micro structure of Annealed Sample-1

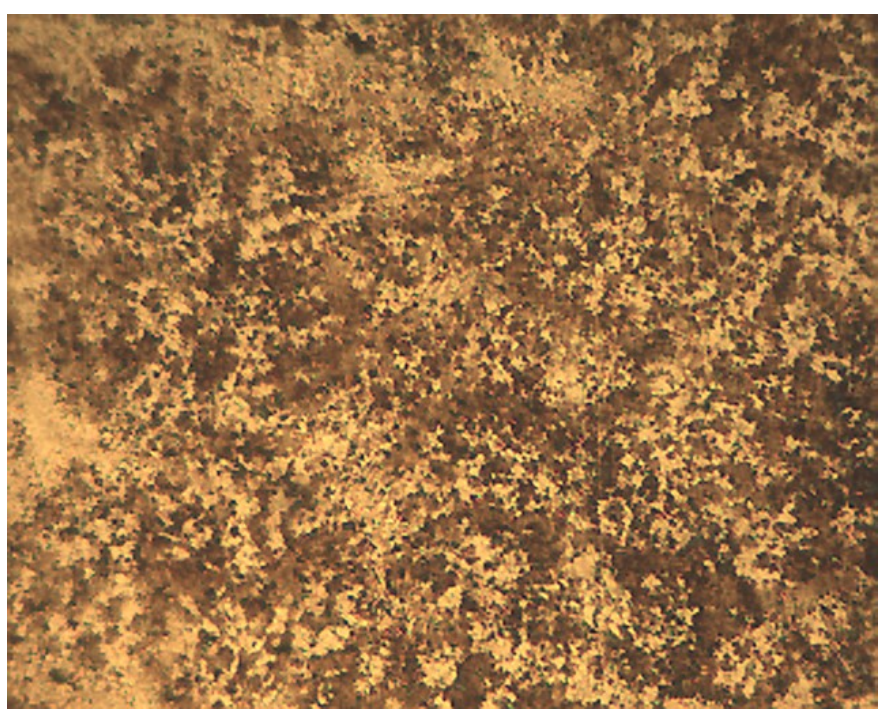

Fig. 3. Micro structure of Annealed Sample-2

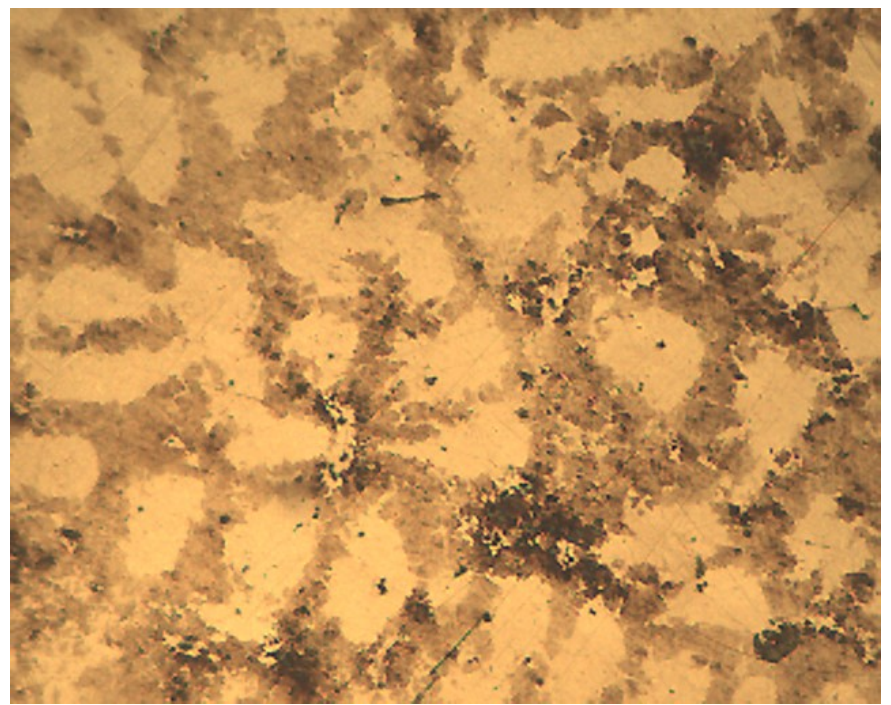

Fig. 4. Micro structure of Annealed Sample-3

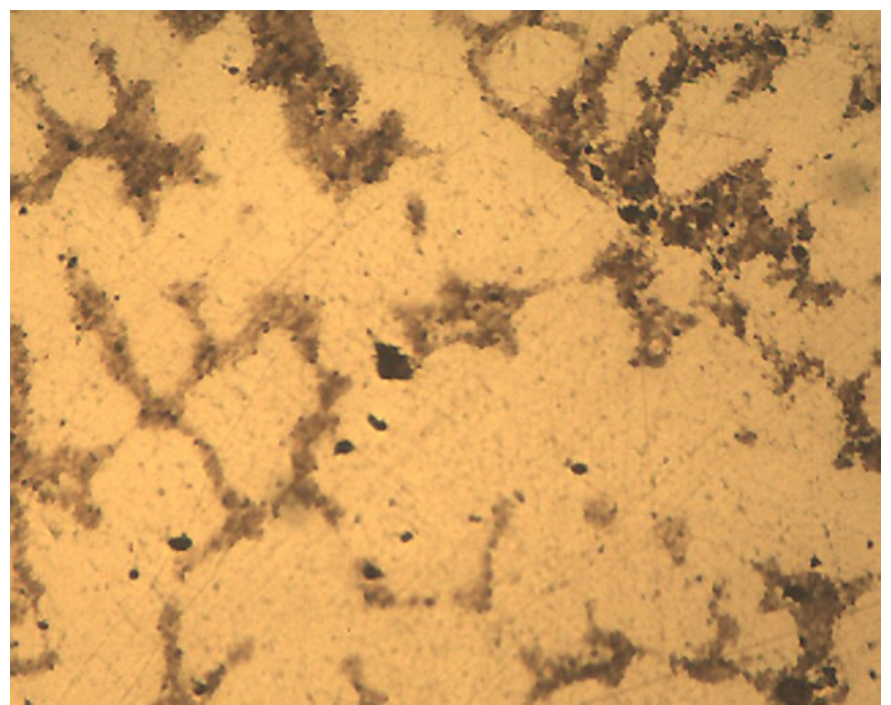

Fig. 5. Micro structure of Annealed Sample- 4

\subsection{Vickers micro hardness test}

This test is performed to find the hardness values of the samples of AISI 4130 steel. Figures 6,7 details about the hardness value of the various steel samples with annealing and case

\section{HARDNESS}

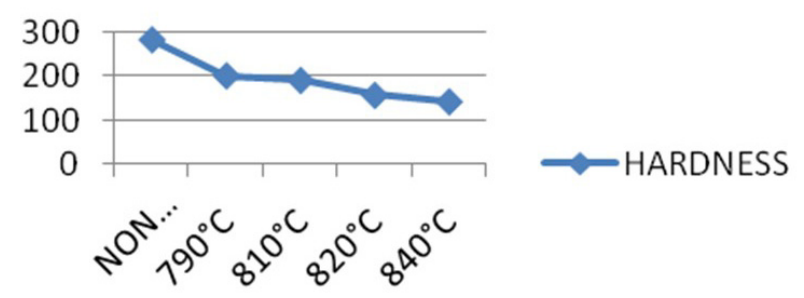

Fig. 6. Relation between the Hardness values of the various AISI 4130 steel samples with annealing 


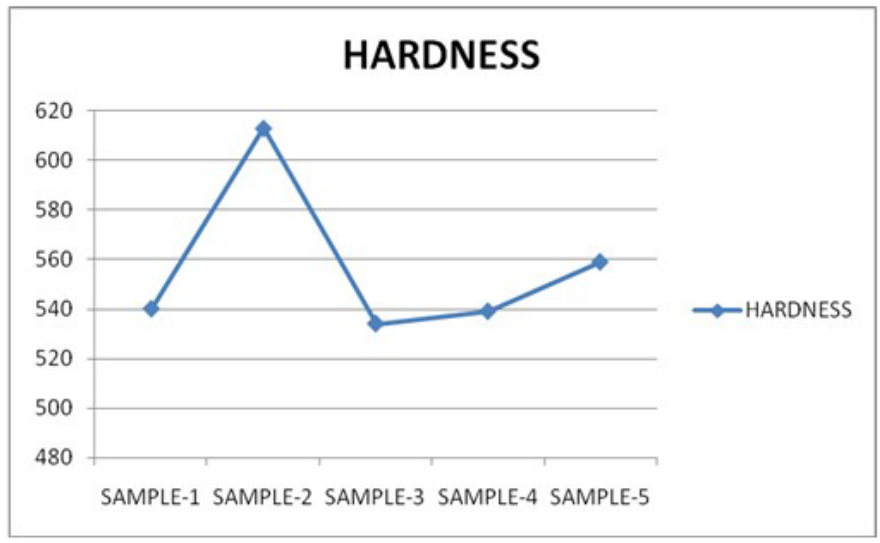

Fig. 7. Relation between the Hardness values of the various AISI 4130

hardened steel. The hardness value changes when the heat treatment temperature changes. Tables 2,3 shows the various hardness value of annealed and case hardened steels.

TABLE 2

Micro hardness value of the Annealed samples

\begin{tabular}{|c|c|}
\hline \hline Samples of AISI 4130 Steel & Micro Hardness Value \\
\hline Non Annealed Sample & 282.33 \\
\hline Annealed Sample-1 & 200.3 \\
\hline Annealed Sample-2 & 190 \\
\hline Annealed Sample-3 & 155.86 \\
\hline Annealed Sample-4 & 141.3 \\
\hline
\end{tabular}

TABLE 3

Micro hardness value of the case hardened samples

\begin{tabular}{|c|c|}
\hline \hline Samples of AISI 4130 Steel & Micro Hardness Value \\
\hline Case hardened Sample-1 & 540 \\
\hline Case hardened Sample-2 & 613 \\
\hline Case hardened Sample-3 & 534 \\
\hline Case hardened Sample-4 & 539 \\
\hline Case hardened Sample-5 & 559 \\
\hline
\end{tabular}

\subsection{Eddy current testing}

In this testing the eddy current hardness sorting instrument is used. This instrument is used to found the variation of the samples based up on the hardness parameter of the samples. The curve is used to sorting the various samples in the heat treatment shop floor. According to the curves formed at the screen in the instrument sorting process is performed. Generally the properties of the material are varied due to the heat treatment operation. This sorting process is must to identify the similar material with varying properties at heat treatment shop floor. Sorting process is based up on the various parameters like Hardness of the material, Case depth of the material, Chemical composition of the material and Microstructure of the material.

\section{Results and Discussion}

The complex plane diagram of the induced voltage obtained on case hardened specimens of AISI 4130 steel is shown in figure 8. This kind of heat treatment on the samples resulting to ensure the required level of the mechanical and physical properties and desired microstructures. With the aid of eddy current testing by using coil probe at $690 \mathrm{KHz}$ frequency the eddy current results are obtained in the form of impedance diagram. Three major factors are affected the eddy current response of the corresponding samples.

a. Hardness of the sample

b. Case depth of the sample

c. Microstructure of the sample

Above 3 criteria are used for sorting the materials at the heat treatment shop floor. This study reveals about the sorting of the annealed samples. In summary the results can be used to separate the heat treated samples with different microstructures. The difference in heat treatment is the main cause of different hardness value in the corresponding samples. The indirect correlation is obtained between the eddy current outputs and hardness of the samples. These results are obtained due to the increasing hardness value of the steel sample. The coercivity increases and magnetic flux decreases. Consequently the impedance decreases by increasing the hardness of the sample. In the whole the hardness property of the various samples of AISI 4130 are studied by eddy current methodology for the evaluation of the hardness properties successfully.

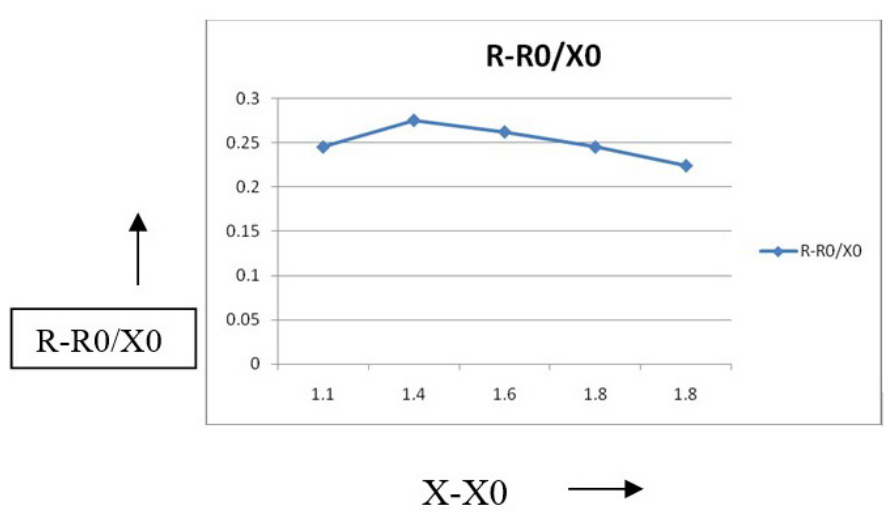

Fig. 8. Variation of EC induced voltage with Vickers hardness of the samples at $690 \mathrm{KHz}$ and phase angle at $68^{\circ}$

\section{Conclusions}

This study reveals that the eddy current testing technique is an effective and means to determine the hardness characterization in the heat treated samples of AISI 4130 steel. By decreasing the hardness value in the samples which had undergone annealing treatment, a clear correlation in eddy current response was observed. The measured parameters (primary and secondary voltages) decreased with increasing the hardness of the heat treated 
samples of AISI 4130 steel. This technique helps to sorting the heat treated specimens based up on the hardness level. Based upon the results from ECT, good samples and bad samples were separated carefully.

\section{REFERENCES}

[1] S. Konoplyuk, Estimation of pearlite fraction in ductile cast irons by eddy Current method. NDT \& E International 43, 360-364 (2010).

[2] S. Konoplyuk, T. Abe, T. Uchimoto, T. Takagi, M. Kurosawa, Characterization of ductile cast iron by eddy current method'. NDT\&E International 38, 623-626 (2005).

[3] S. Ghanei, M. Kashefi, M. Mazinani, Eddy Current Non Destructive Evaluation of dual phase steel, Materials and Design 50, 491-496 (2013).

[4] K.V. Rajkumar, B.P.C. Rao, B. Sasi, A. Kumar, T. Jayakumar, B. Raj, K.K. Ray, Characterization of ageing behaviour in M250 grade maraging steel Using Eddy Current Non Destructive methodology, Materials Science and Engineering A 464, 233-240.

[5] M. Zergoug, S. Lebaili, H. Boudjellal, A. Benchaaln, Relation between mechanical microhardness and impedance variations in eddu current testing. NDT \& E International 37, 65-72 (2004).

[6] D. Mercier, J. Lesage, X. Decoopman, D. Chicot, Eddy currents and Hardness testing for evaluation of steel decarburizing, NDT \& E International 39, 652-660 (2006).

[7] T. Uchimoto, T. Takagi, S. Konoplyuk, T. Abe, H. Huang, M. Kurosawa, Eddy Current evaluation of cast irons for material characterization, Journal of Magnetism and magnetic materials, pp 258-259 (2003).

[8] S.H. Khan, A. Farhad, A. Nusair Khan, M.A. Iqbal, Pearlite determination of Plain carbon steel by eddy current method, Journal of Materials Processing Technology 200, 316-318 (2003).

[9] B.P.C. Rao, Eddy Current Testing: Basics.

[10] A. Abbasian, M. Khasefi, E. Mohmadzade Beiraki, Quality control of precipitation hardened aluminium alloy parts via eddy current non destructive evaluation, Iranian Journal of Material Science and Engineering 12, 84-87 (2015). 